\title{
Removing Phosphonate Antiscalants from Membrane Concentrate Solutions using Granular Ferric Hydroxide
}

\author{
Yingying Chen, James C. Baygents and James Farrel1* \\ Department of Chemical and Environmental Engineering \\ University of Arizona, Tucson, AZ 85721
}

*corresponding author: farrellj@email.arizona.edu; 520 940-0487 


\begin{abstract}
Phosphonate antiscalants are commonly used in membrane desalination to prevent fouling by mineral scale. In many circumstances, it is desirable to remove these compounds before concentrate disposal or further treatment. The goal of this research was to determine if the kinetics of phosphonate adsorption and desorption from granular ferric hydroxide (GFH) are sufficiently fast for GFH to be used in packed bed adsorption systems for antiscalant removal from membrane concentrate solutions. Well-stirred batch experiments were performed to investigate the adsorption kinetics of Permatreat $191^{\circledR}$ (PT191) and nitrilotri(methylphosphonic) acid (NTMP) onto GFH. Uptake of both compounds was slow and continued over the course of 6 days. Adsorption isotherms measured after 24 hours elapsed showed initial concentration effects, whereby the isotherms were dependent on the initial adsorbate concentration in solution. This can be attributed to chemical adsorption reactions with faster rates of bond formation than bond breaking. Strong phosphonate adsorption in high $\mathrm{pH}$ solutions and high activation barriers for desorption resulted in slow kinetics for adsorbent regeneration by $\mathrm{NaOH}$ solutions. Desorption rates were bimodal, with $40-50 \%$ of the adsorbed phosphonate being released on a time scale of 10-24 hours, while the remaining fraction was released approximately one order of magnitude more slowly. Complete regeneration could not be achieved, even after eluting the adsorbent columns with more than 300 bed volumes of $1.0 \mathrm{~mol} / \mathrm{L} \mathrm{NaOH}$. The inability to regenerate the adsorbent in an efficient manner likely precludes its use for cost-effective antiscalant removal from membrane concentrate solutions.
\end{abstract}

keywords: phosphonate, granular ferric hydroxide, surface complexation, membrane concentrate, NTMP, nitrilotri(methylphosphonic) acid 


\section{Introduction}

Antiscalant compounds are commonly used during nanofiltration (NF) and reverse osmosis (RO) to prevent membrane fouling by mineral scale. The most commonly used type of antiscalants are phosphonate compounds. Similar to phosphate, phosphonate compounds have a high affinity for $\mathrm{Ca}^{2+}$ and other scale forming ions, such as $\mathrm{Ba}^{2+}, \mathrm{Mg}^{2+}$ and $\mathrm{Fe}^{3+}$ [1]. Phosphonate compounds inhibit scale formation by interfering with crystallization of scale forming minerals, and delaying or completely preventing nucleation of mineral precipitates [2].

In many water treatment operations, the membrane concentrate is subjected to a second stage $\mathrm{NF} / \mathrm{RO}$ process. Increased water recovery can be achieved using multistage processes that include a precipitation step on the primary NF/RO concentrate [3]. When antiscalant compounds are used, they interfere with mineral precipitation from the concentrate solution [4]. Thus, it is desirable to remove antiscalant compounds from the primary concentrate prior to the precipitation step. In situations where the membrane concentrate is disposed of in the ocean, phosphonate removal is also desirable to avoid adding phosphate that may promote algal blooms $[5]$.

Removal of phosphonate compounds from membrane concentrate solutions requires an adsorbent that reacts with the phosphonate group via chemical adsorption, rather than by electrostatic attraction or ion exchange. This is necessary since the concentration of the antiscalant compound is usually less than $0.1 \mathrm{mM}$, while the concentrations of other anions, such

as $\mathrm{Cl}^{-}, \mathrm{SO}_{4}{ }^{2-}$, and $\mathrm{HCO}_{3}{ }^{-}$are typically one to two orders of magnitude greater. Adsorbents based on ferric hydroxide have been proposed for removing phosphonate antiscalants from membrane concentrate solutions [6-8]. 
The mechanisms of phosphonate adsorption to iron oxide minerals and amorphous ferric hydroxide have been studied by several investigators using spectroscopic and quantum chemistry methods [9-14]. The mechanisms of phosphonate uptake by ferric hydroxides are complex, and involve several adsorption mechanisms that include both physical and chemical adsorption. A recent study using quantum chemistry simulations showed that physical adsorption of the antiscalant, nitrilotri(methylphosphonic) acid (NTMP), on ferric hydroxide is promoted by electrostatic effects, and charge assisted hydrogen bonding [9]. NTMP is a polyprotic acid containing six ionizable $-\mathrm{POH}$ groups and one strong base group. The $\mathrm{pK}_{\mathrm{a}}$ values for the six phosphoric acid groups are: $<0,<0,1.50,4.62,5.90,7.25$, and the $\mathrm{pK}_{\mathrm{a}}$ for the strong base group is 14.2 [15]. Thus, at circumneutral $\mathrm{pH}$ values, NTMP will carry a net negative charge ranging from -3 to -5 that increases with increasing $\mathrm{pH}$ value. In addition to physical adsorption, phosphonate compounds are known to form chemical adsorption complexes with ferric hydroxide [9,12-14]. These complexes involve ligand exchange reactions in which an -OH or $\mathrm{OH}_{2}$ ligand attached to $\mathrm{Fe}^{3+}$ is replaced by a phosphonate. Adsorption complexes involving a single $\mathrm{P}-\mathrm{O}-\mathrm{Fe}$ bond are termed, monodentate mononuclear complexes. Bidentate mononuclear complexes may form that involve two Fe-O-P bonds to the same Fe atom. Two P-O-Fe bonds on adjacent $\mathrm{Fe}$ atoms may also form. This type of complex is known as a bidentate binuclear complex. For phosphonate compounds that contain more than one phosphonate group, multiple types of bonding may occur for a single adsorbate molecule [9]. In addition, $\mathrm{Ca}^{2+}$ ions may also be involved in ternary complexes between ferric hydroxide and phosphonate groups $[9,16]$.

Chemical adsorption reactions generally have activation barriers associated with breaking and forming chemical bonds. A previous study using quantum chemistry modeling has shown that adsorption of NTMP on ferric hydroxide has activation barriers ranging from $0 \mathrm{kcal} / \mathrm{mol}$ for 
physical adsorption, and 8.5 to $53 \mathrm{kcal} / \mathrm{mol}$ for chemical adsorption [9]. For desorption of NTMP from ferric hydroxide, activation barriers ranged from 36 to $53 \mathrm{kcal} / \mathrm{mol}$, depending on the type of complex [9]. At room temperature, these activation barriers are significantly greater than the average thermal energy per molecule, and can result in slow equilibration for both adsorption and desorption reactions. Higher activation barriers for desorption, as compared to adsorption, can result in metastable equilibrium and adsorption isotherms that are apparently influenced by the initial concentration of the adsorbate in solution [9].

A previous study has reported that adsorption of NTMP on a granular ferric hydroxide (GFH) adsorbent required 3 to 9 hours to reach equilibrium, and depended on the initial concentration of NTMP in solution [6]. The slow approach to equilibrium was attributed to diffusional mass transfer limitations, and the effect of activation barriers on rates of adsorption and desorption were not considered. Batch adsorption isotherms were measured after 24 hours of equilibration. Similarly, a second batch study has reported adsorption isotherms for NTMP on GFH measured after 24 hours of equilibration [8].

We hypothesize that high activation barriers for chemical bond formation and bond breaking of phosphonate antiscalants will result in slow kinetics for both adsorption and desorption in packed bed treatment systems. Slow adsorption kinetics may result in early breakthrough in flow-through adsorbent beds. Slow desorption will make adsorbent regeneration difficult, possibly requiring large volumes of regenerant solution. The goal of this study was to investigate whether the kinetics of phosphonate adsorption and desorption from GFH are sufficiently fast to enable it to be used in practical treatment systems for antiscalant removal. Practical treatment systems commonly employ empty bed contact times on the order of 10 minutes and can be regenerated on-site. Towards those ends, column breakthrough experiments 
and adsorption isotherms were measured for a commercial phosphonate antiscalant and for NTMP on a commercially available GFH adsorbent. The effectiveness of adsorbent regeneration using 0.10 and $1.0 \mathrm{~mol} / \mathrm{L} \mathrm{NaOH}$ solutions was also investigated.

\section{Materials and Methods}

\subsection{Adsorbent}

The adsorbent used in this study was Granular Ferric Hydroxide ${ }^{\circledR}$ (GFH), and was obtained from GEH Wasserchemie (Osnabruck, Germany). GFH consists predominantly of the mineral akaganeite $(\beta-\mathrm{FeOOH})$, and was developed for removal of arsenate and arsenite from potable water [17-19]. The material was used as-received, with manufacturer's reported specifications of $300 \mathrm{~m}^{2} / \mathrm{g}$ surface area, and 0.2 to $2.0 \mathrm{~mm}$ particle diameters. Drying the GFH for 24 hours at $120{ }^{\circ} \mathrm{C}$ resulted in a $45 \%$ weight loss, which is indicative of the water content. All results are presented on an as-received mass basis.

\subsection{Synthetic NF Concentrate}

The composition of the water used in the isotherm and column experiments was based on NF concentrate generated in a previous investigation [4]. The NF concentrate was produced from Central Arizona Project (CAP) water as delivered to Tucson, AZ at $85 \%$ recovery. The simulated NF concentrate included only the major ions listed in Table 1. Solutions were prepared in $18 \mathrm{M} \Omega$-cm ultrapure water (UPW) using ACS grade $\mathrm{H}_{2} \mathrm{SO}_{4}, \mathrm{CaCl}_{2}, \mathrm{Na}_{2} \mathrm{CO}_{3}$, $\mathrm{Na}_{2} \mathrm{SO}_{4}, \mathrm{MgCl}_{2}, \mathrm{NaOH}$, and $\mathrm{HCl}$ from Fisher Scientific. Two different antiscalants were tested, Permatreat $191{ }^{\circledR}$ (PT191) from Nalco (Naperville, IL), and NTMP of $\geq 97 \%$ purity from SigmaAldrich (St. Louis, MO). PT191 is a proprietary mixture of phosphonate compounds plus a terpolymer composed of acrylic acid, acrylamide, and acrylamidomethylsulphonic acid [20]. In 
preparing the NF concentrate, the antiscalants were dosed in accord with the manufacturer's recommendation. Because the composition of the phosphonate compounds in the PT191 are unknown, phosphonate concentrations are reported on a mg phosphorous per liter basis (mgP/L). Phosphorous concentrations were measured using an Agilent model 5100 synchronous vertical dual view inductively coupled plasma optical emission spectrophotometer (ICP-OES) using a wavelength of $213.618 \mathrm{~nm}$. Three calibration standards with concentrations of $0.10,1.0$ and $10.0 \mathrm{mg}-\mathrm{P} / \mathrm{L}$ were prepared in UPW. The linear calibration curve had an $\mathrm{R}^{2}$ value of 0.9999 .

Table 1 . Composition of the $\mathrm{pH}=8.3$ synthetic NF concentrate used in isotherm and column experiments.

\begin{tabular}{ccc|ccc}
\hline Cation & $\begin{array}{c}\text { Concentration } \\
(\mathrm{mmol} / \mathrm{L})\end{array}$ & $\begin{array}{c}\text { Concentration } \\
(\mathrm{mg} / \mathrm{L})\end{array}$ & Anion & $\begin{array}{c}\text { Concentration } \\
(\mathrm{mmol} / \mathrm{L})\end{array}$ & $\begin{array}{c}\text { Concentration } \\
(\mathrm{mg} / \mathrm{L})\end{array}$ \\
\hline $\mathrm{Na}^{+}$ & 29.0 & 667 & $\mathrm{SO}_{4}{ }^{2-}$ & 13.0 & 1250 \\
$\mathrm{Ca}^{2+}$ & 8.50 & 340 & $\mathrm{Cl}^{-}$ & 29.5 & 1050 \\
$\mathrm{Mg}^{2+}$ & 6.25 & 150 & $\mathrm{HCO}_{3}^{-}$ & 3.00 & 300 as $\mathrm{CaCO}_{3}$ \\
\hline
\end{tabular}

\subsection{Column Breakthrough and Regeneration Experiments}

Column breakthrough experiments were performed using 1-2 grams of each adsorbentGFH packed into a $0.8 \mathrm{~cm}$ diameter by $9 \mathrm{~cm}$ long glass column and held in place using glass wool. The columns were operated at an empty bed contact time of 2.0 minutes in up-flow mode at a flow rate of $1.0 \mathrm{ml} / \mathrm{min}$ using liquid chromatography pumps. The regeneration experiments were performed using $0.10 \mathrm{~mol} / \mathrm{L}$ or $1.0 \mathrm{~mol} / \mathrm{L} \mathrm{NaOH}$ at flow rates of $0.05 \mathrm{ml} / \mathrm{min}$ or $0.25 \mathrm{ml} / \mathrm{min}$. After regeneration, the columns were rinsed with UPW to bring down the effluent $\mathrm{pH}$ to $\sim 8.5$ 
before reuse. Effluent samples from each column were collected using a Gilson FC204 fraction collector. As a check on the mass balance of each adsorbate, samples of the adsorbent were removed from the columns after use and dissolved in $1.5 \mathrm{~mol} / \mathrm{L} \mathrm{HCl}$. The liquor was then analyzed for its phosphorous content to determine the amount of adsorbed phosphonate that was not removed during the regeneration process.

\subsection{Adsorption Isotherm Experiments}

Adsorption isotherms were obtained via addition of 10 to $4000 \mathrm{mg}$ of GFH to synthetic concentrate solutions contained in polyethylene bottles. Three initial phosphorous concentrations for each adsorbate were tested: $0.60,3.0$ and $9.0 \mathrm{mg} / \mathrm{L}$. For the NTMP, these phosphorous concentrations corresponded to $2.0,10$ and $30 \mathrm{mg}-\mathrm{NTMP} / \mathrm{L}$. Isotherms were measured at $20{ }^{\circ} \mathrm{C}$ at an initial $\mathrm{pH}$ value of 8.3. Desorption isotherms were measured in synthetic membrane concentrate solution at a $\mathrm{pH}$ value of 8.3 , and in $0.10 \mathrm{~mol} / \mathrm{L} \mathrm{NaOH}$ at a $\mathrm{pH}$ value of 12.7. The suspensions were placed on an orbital shaker operating at $80 \mathrm{rpm}$ and were sampled over a period of 24 to 147 hours. Samples were filtered with $0.45 \mu \mathrm{m}$ syringe filters and acidified before analysis using $\mathrm{HNO}_{3}$. Triplicate samples were taken and the reported values represent the mean of the three samples. Freundlich and Langmuir isotherm models were fit to the experimental data using a non-linear least squares algorithm as implemented in Origin ${ }^{\circledR} 8.5$ [21].

\section{Results and Discussion}

\subsection{Adsorption Isotherms}

Adsorption isotherms measured over a period of 147 hours for an initial PT191 solution concentration of $3.0 \mathrm{mg}-\mathrm{P} / \mathrm{L}$ are shown in Figure 1. The increasing adsorption with time shows 
that these isotherms are not at equilibrium. The isotherms can be adequately described by both the Freundlich and Langmuir isotherm models, whose parameters are given in Table 2. However, due to the non-equilibrium and the multiple modes of physical and chemical adsorption, the isotherm fits are empirical and do not infer any particular mechanism of adsorption. The slow approach to equilibrium for adsorption to ferric hydroxide has been observed for arsenate, which adsorbs via similar mechanisms as phosphonate. For example, Fuller et al. (1993) reported that $\sim 75 \%$ of arsenate uptake by ferrihydrite occurred in less than five minutes, but additional adsorption continued to occur until the experiments were terminated after 8 days [22]. In flowthrough treatment systems, the slow approach to equilibrium may result in adsorbent loadings that are much lower than anticipated based on equilibrium isotherms. In many cases, adsorbents are regenerated on a daily basis, and thus the loading after 24 hours may be the best indication of adsorption capacity in a flow-through treatment system.

Adsorption isotherms measured after 24 hours for PT191 for three initial solution concentrations are shown in Figure 2. Freundlich and Langmuir isotherm parameters for this data are listed in Table 3. Interestingly, the initial concentration in the solution had a significant effect on the amount of phosphonate uptake after 24 hours. This phenomenon has been previously reported for arsenate adsorption on titanium dioxide, and has been termed the "initial concentration effect" [23]. This effect can be attributed to kinetically irreversible adsorption, where rates of desorption can be orders of magnitude slower than rates of adsorption [24,25]. In this case, exposure of the outer layer of an adsorbent granule to a high concentration of an adsorbate results in a high amount of uptake in that layer that is not released and redistributed over the entire granule when the overall solution concentration decreases to its lower final value. Given sufficient time for equilibration, the initial concentration effect will disappear. 
Adsorption isotherms measured over a period of 147 hours for an initial NTMP solution concentration of $3.0 \mathrm{mg}-\mathrm{P} / \mathrm{L}$ are shown in Figure 3. Table 3 lists Freundlich and Langmuir isotherm parameters for each data set. The slow approach to equilibrium was also demonstrated for NTMP adsorption. There were no measurable $\mathrm{pH}$ changes over the course of any of the adsorption experiments. This can be attributed to the buffering capacity of the $3 \mathrm{mM} \mathrm{HCO}_{3}^{-}$in the simulated membrane concentrate solutions.

Figure 4 shows adsorption isotherms for NTMP measured after 24 hours for initial concentrations of $0.60,3.0$ and $9.0 \mathrm{mg}-\mathrm{P} / \mathrm{L}$. The NTMP isotherms also show an initial concentration effect. However, the effect is opposite of that shown by the PT191. For the case of NTMP, greater adsorption was shown for lower initial concentrations after 24 hours elapsed. We are not aware of any previous reports of this phenomenon. However, the porous structure of akaganeite may provide an explanation for this type of behavior [26].

The structure of akaganeite is composed of $\mathrm{Fe}^{3+}$ in octahedral coordination with oxygen atoms. These octahedral structures are arranged in a manner that forms channels with a diameter of $5.6 \AA[26]$. Because NTMP has more than one phosphonate group, it can form two bonds with two $\mathrm{Fe}^{3+}$ atoms on opposite sides of a channel opening. This would result in blocking the diffusion of other NTMP species to adsorption sites inside the channel. Thus, one possible explanation for the unusual initial concentration effect observed in Figure 4 is that a higher initial concentration of NTMP in solution resulted in a greater amount of slowly reversible pore blocking. Thus, pores blocked by high initial NTMP adsorption when first exposed to the solution were unblocked very slowly as the NTMP solution concentration declined during the equilibration period. In this manner, higher initial NTMP concentrations resulted in greater blockage of interior adsorption sites. The fact that this behavior was not observed with the 
phosphonate compounds in the PT191 may result from these phosphonates having only a single $\mathrm{PO}_{3}$ functional group, and thus can only adsorb at a single $\mathrm{Fe}^{3+}$ site.

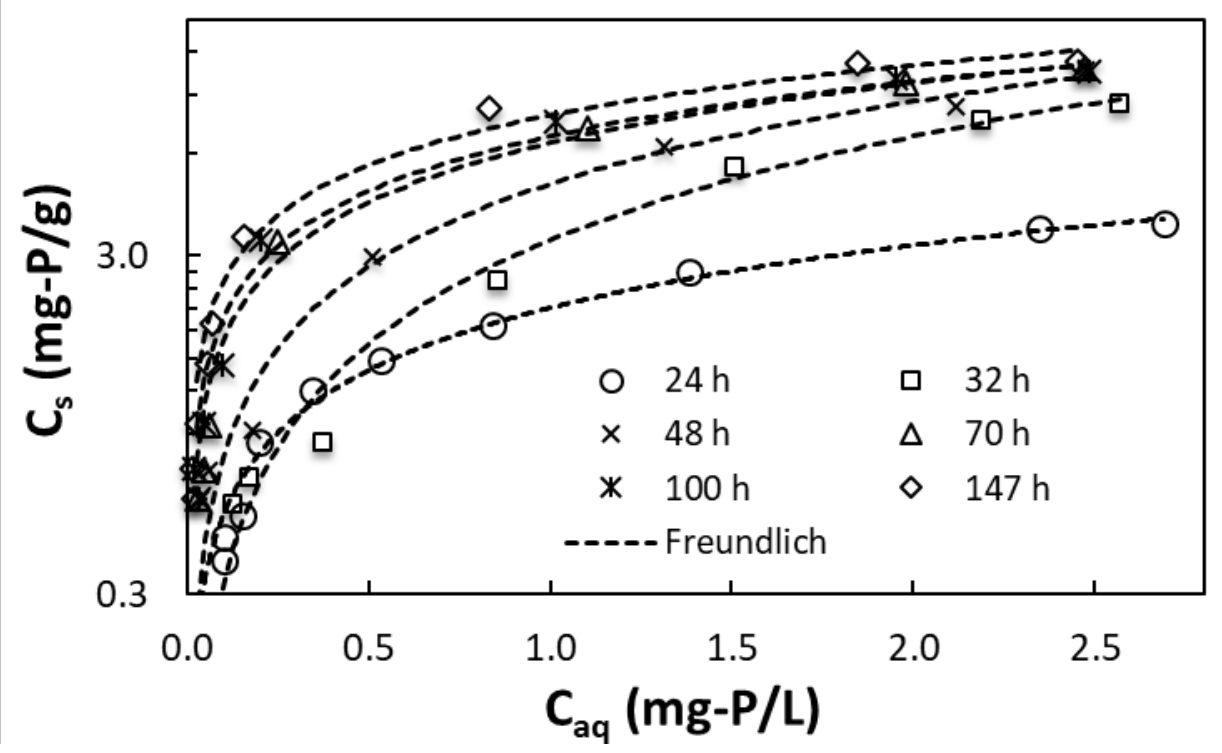

Figure 1. Adsorption isotherms measured after different elapsed times for PT191 with initial concentrations of $3.0 \mathrm{mg}-\mathrm{P} / \mathrm{L}$. Also shown are fits to the Freundlich isotherm model with parameters listed in Table 2. Note the logarithmic scale on the ordinate in order to achieve better visual separation between data sets. 


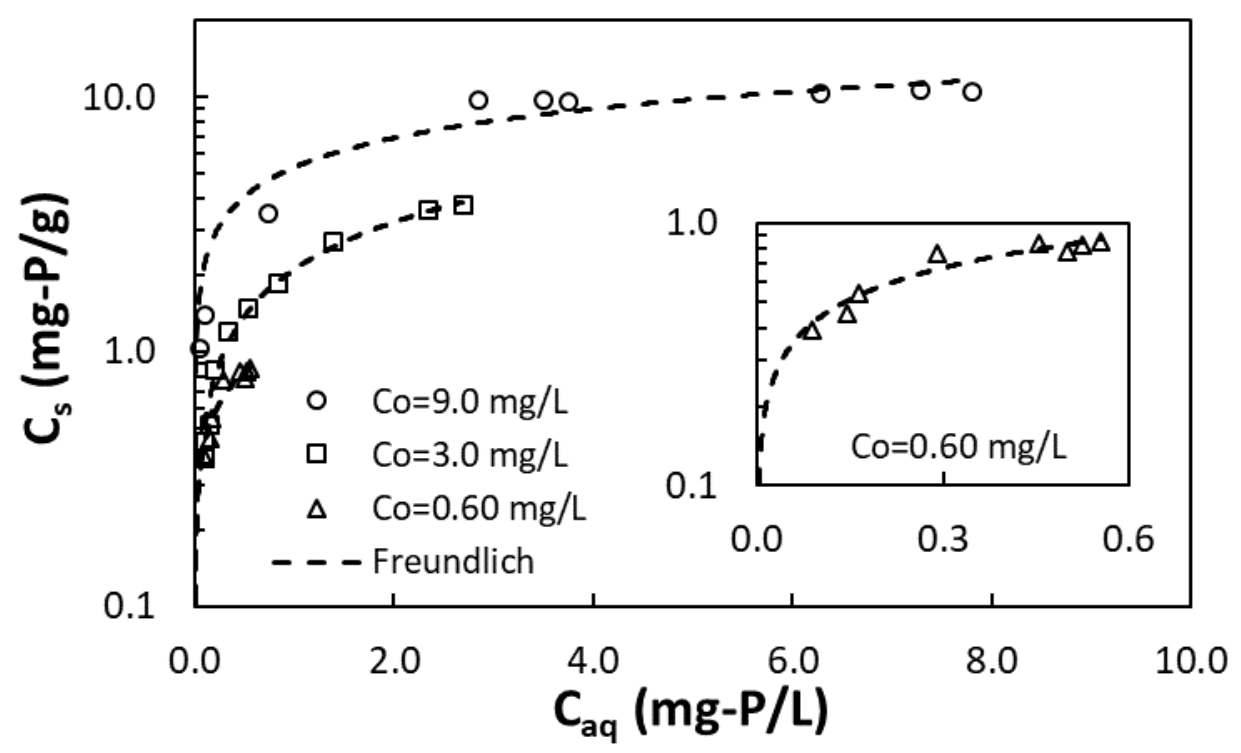

Figure 2. Adsorption isotherms for PT191 with initial concentrations of 0.60, 3.0 and $9.0 \mathrm{mg}-$ $\mathrm{P} / \mathrm{L}$ at 24 hours. Also shown are fits to the Freundlich isotherm model with parameters listed in Table 3.

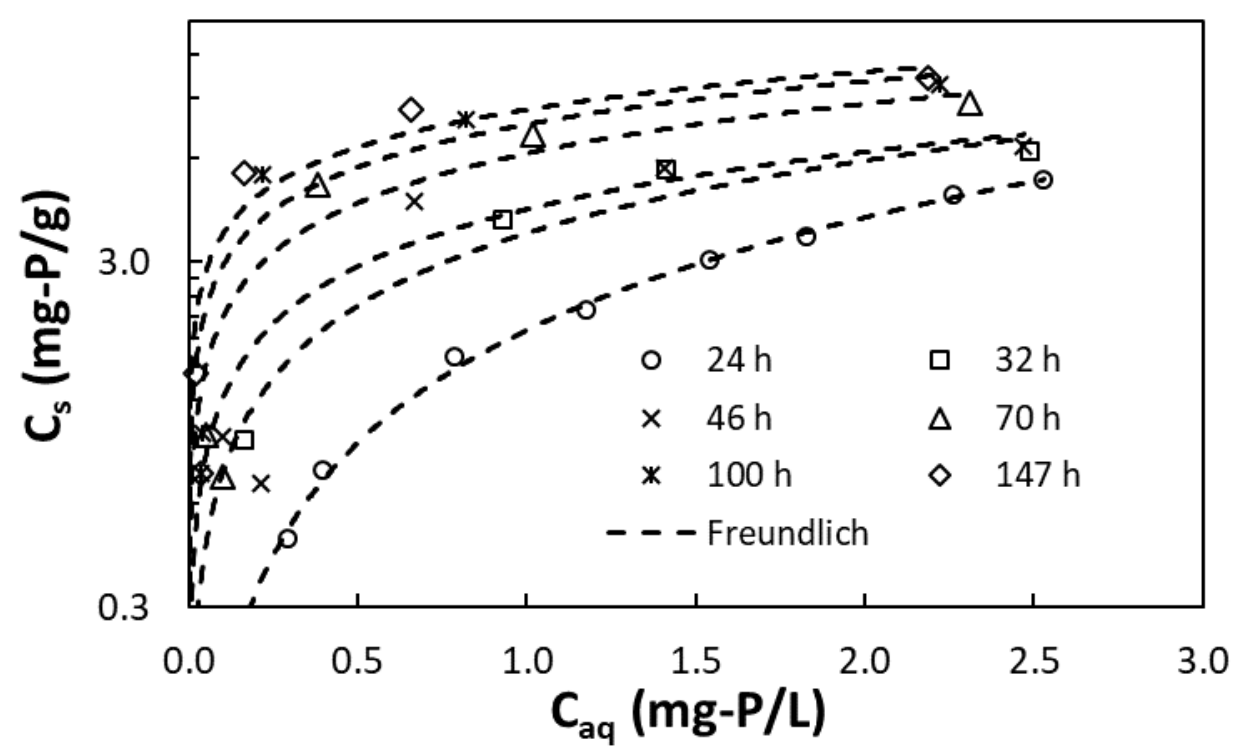

Figure 3. Adsorption isotherms measured after different elapsed times for NTMP with initial concentrations of $3.0 \mathrm{mg}-\mathrm{P} / \mathrm{L}$. Also shown are fits to the Freundlich isotherm model with parameters listed in Table 4. 


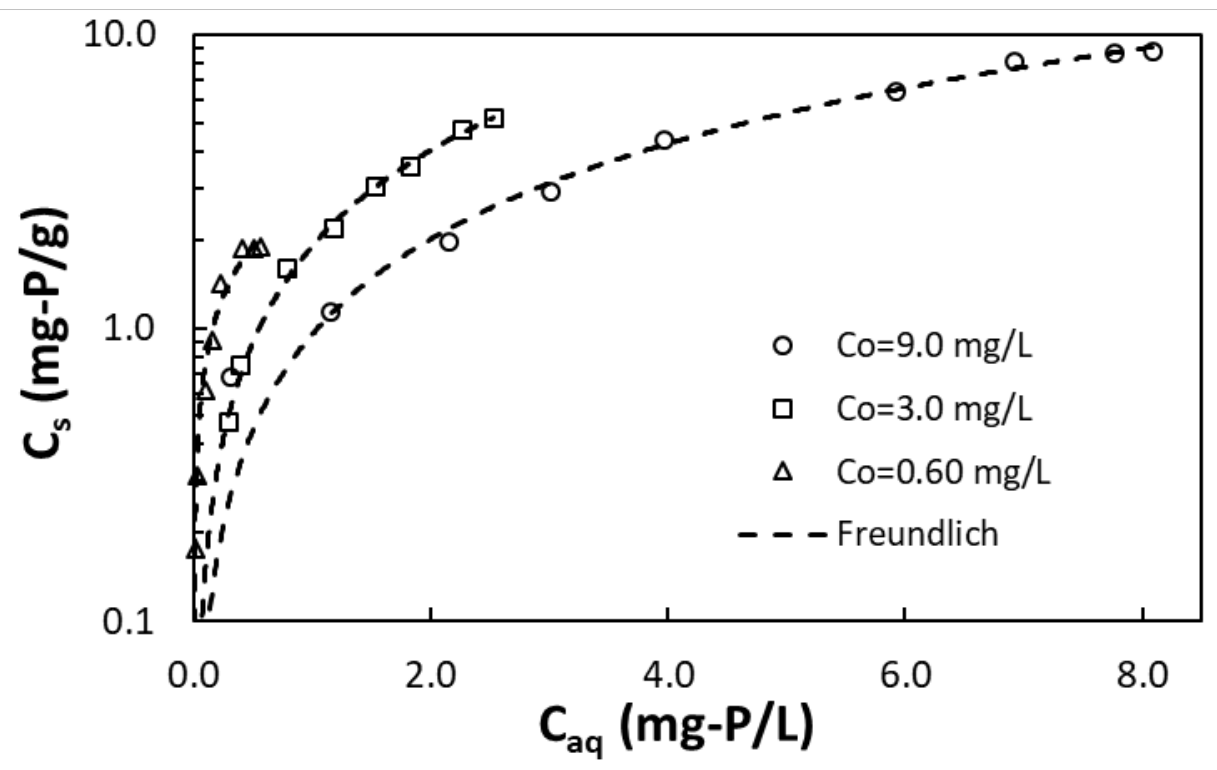

Figure 4. Adsorption isotherms for NTMP with initial concentrations of $0.60,3.0$ and $9.0 \mathrm{mg}-\mathrm{P} / \mathrm{L}$ at 24 hours. Also shown are fits to the Freundlich isotherm model with parameters listed in Table 3.

Table 2. Langmuir and Freundlich isotherm parameters for PT191 for initial solution concentrations of $3.0 \mathrm{mg}-\mathrm{P} / \mathrm{L}$. The Langmuir model is given by: $\mathrm{C}_{\mathrm{s}}=\frac{\mathrm{C}_{\mathrm{smax}} \times \mathrm{b} \times \mathrm{C}_{\mathrm{aq}}}{1+\mathrm{b} \times \mathrm{C}_{\mathrm{aq}}}$. The Freundlich model is given by: $\mathrm{C}_{\mathrm{s}}=\mathrm{K}_{F} \times \mathrm{C}_{\mathrm{aq}}^{\mathrm{n}}$.

\begin{tabular}{c|ccc|ccc}
\hline \multirow{2}{*}{ Time } & \multicolumn{3}{|c|}{ Langmuir } & \multicolumn{3}{c}{ Freundlich } \\
& $\mathrm{C}_{\mathrm{smax}}$ & $\mathrm{b}$ & $\mathrm{R}^{2}$ & $\mathrm{~K}_{\mathrm{F}}$ & $\mathrm{n}$ & $\mathrm{R}^{2}$ \\
\hline $24 \mathrm{~h}$ & 5.89 & 0.64 & $99.3 \%$ & 2.11 & 0.61 & $99.4 \%$ \\
$32 \mathrm{~h}$ & 623.9 & 0.00549 & $99.1 \%$ & 3.34 & 1.02 & $99.1 \%$ \\
$48 \mathrm{~h}$ & 34.02 & 0.17 & $98.9 \%$ & 4.89 & 0.81 & $99.1 \%$ \\
$70 \mathrm{~h}$ & 15.04 & 0.93 & $99.5 \%$ & 6.47 & 0.58 & $99.5 \%$ \\
$100 \mathrm{~h}$ & 13.4 & 1.40 & $99.6 \%$ & 6.77 & 0.54 & $98.6 \%$ \\
$147 \mathrm{~h}$ & 13.47 & 2.11 & $99.7 \%$ & 7.8 & 0.49 & $98.1 \%$ \\
\hline
\end{tabular}


Table 3. Langmuir and Freundlich parameters for isotherms measured after 24 hours elapsed for PT191 and NTMP for three initial solution concentrations.

\begin{tabular}{c|c|ccc|ccc}
\hline \multirow{2}{*}{ PT191 } & Initial Concentration & \multicolumn{3}{|c|}{ Langmuir isotherm } & \multicolumn{3}{c}{ Freundlich isotherm } \\
& $(\mathrm{mg} \mathrm{P} / \mathrm{L})$ & $\mathrm{C}_{\text {smax }}$ & $\mathrm{b}$ & $\mathrm{R}^{2}$ & $\mathrm{~K}_{\mathrm{F}}$ & $\mathrm{n}$ & $\mathrm{R}^{2}$ \\
\hline \multirow{3}{*}{ NTMP } & 0.60 & 1.12 & 5.78 & $98.0 \%$ & 1.10 & 0.40 & $96.9 \%$ \\
& 3.0 & 5.89 & 0.64 & $99.3 \%$ & 2.11 & 0.61 & $99.4 \%$ \\
& 9.0 & 12.75 & 0.78 & $98.0 \%$ & 5.30 & 0.38 & $93.8 \%$ \\
\hline \multirow{3}{*}{ No } & 3.0 & 7875 & $2.56 \mathrm{E}-04$ & $99.6 \%$ & 1.91 & 1.08 & $99.8 \%$ \\
& 9.0 & 10140 & $1.09 \mathrm{E}-04$ & $99.2 \%$ & 0.95 & 1.08 & $99.4 \%$ \\
\hline
\end{tabular}

Table 4. Langmuir and Freundlich isotherm parameters for NTMP for initial solution concentrations of $3.0 \mathrm{mg}-\mathrm{P} / \mathrm{L}$.

\begin{tabular}{c|ccc|ccc}
\hline \multirow{2}{*}{ Time } & \multicolumn{3}{|c|}{ Langmuir } & \multicolumn{3}{c}{ Freundlich } \\
& $\mathrm{C}_{\text {smax }}$ & $\mathrm{b}$ & $\mathrm{R}^{2}$ & $\mathrm{~K}_{\mathrm{F}}$ & $\mathrm{n}$ & $\mathrm{R}^{2}$ \\
\hline $24 \mathrm{~h}$ & 7875 & $2.56 \mathrm{E}-04$ & $99.6 \%$ & 1.91 & 1.08 & $99.8 \%$ \\
$32 \mathrm{~h}$ & 12.86 & 0.43 & $93.7 \%$ & 3.64 & 0.70 & $90.7 \%$ \\
$46 \mathrm{~h}$ & 9.41 & 1.02 & $95.3 \%$ & 4.27 & 0.55 & $90.8 \%$ \\
$70 \mathrm{~h}$ & 10.8 & 1.83 & $97.5 \%$ & 6.19 & 0.48 & $91.9 \%$ \\
$100 \mathrm{~h}$ & 10.99 & 3.43 & $98.5 \%$ & 7.52 & 0.41 & $92.1 \%$ \\
$147 \mathrm{~h}$ & 11.18 & 4.93 & $98.3 \%$ & 8.30 & 0.36 & $91.3 \%$ \\
\hline
\end{tabular}

The effect of hardness ions on phosphonate adsorption was also investigated. Figure 5 compares isotherms for PT191 in the simulated NF concentrate and in $\mathrm{NaCl}$ solutions, both at $\mathrm{pH}=8.3$ and an ionic strength of $86.25 \mathrm{mmol} / \mathrm{L}$. The nearly identical isotherms in both solutions indicates that $\mathrm{Ca}^{2+}$ and $\mathrm{Mg}^{2+}$ ions had no effect on phosphonate adsorption from the PT191 
solutions. This behavior contrasts with that shown by the NTMP, as illustrated in Figure 6 . The presence of hardness ions increased NTMP adsorption by approximately a factor of 2.5. This can be explained by the high affinity of NTMP for divalent cations. Complexation of ionized phosphonate groups with $\mathrm{Ca}^{2+}$ or $\mathrm{Mg}^{2+}$ will neutralize some of the negative charges on the NTMP molecule, thereby decreasing its aqueous solubility and increasing its adsorption. The absence of any effect of hardness ions on adsorption of PT191 is consistent with the phosphonate in PT191 not being able to simultaneously form complexes with ferric hydroxide and divalent cations. This suggests that the PT191 contains only monofunctional phosphonate compounds.

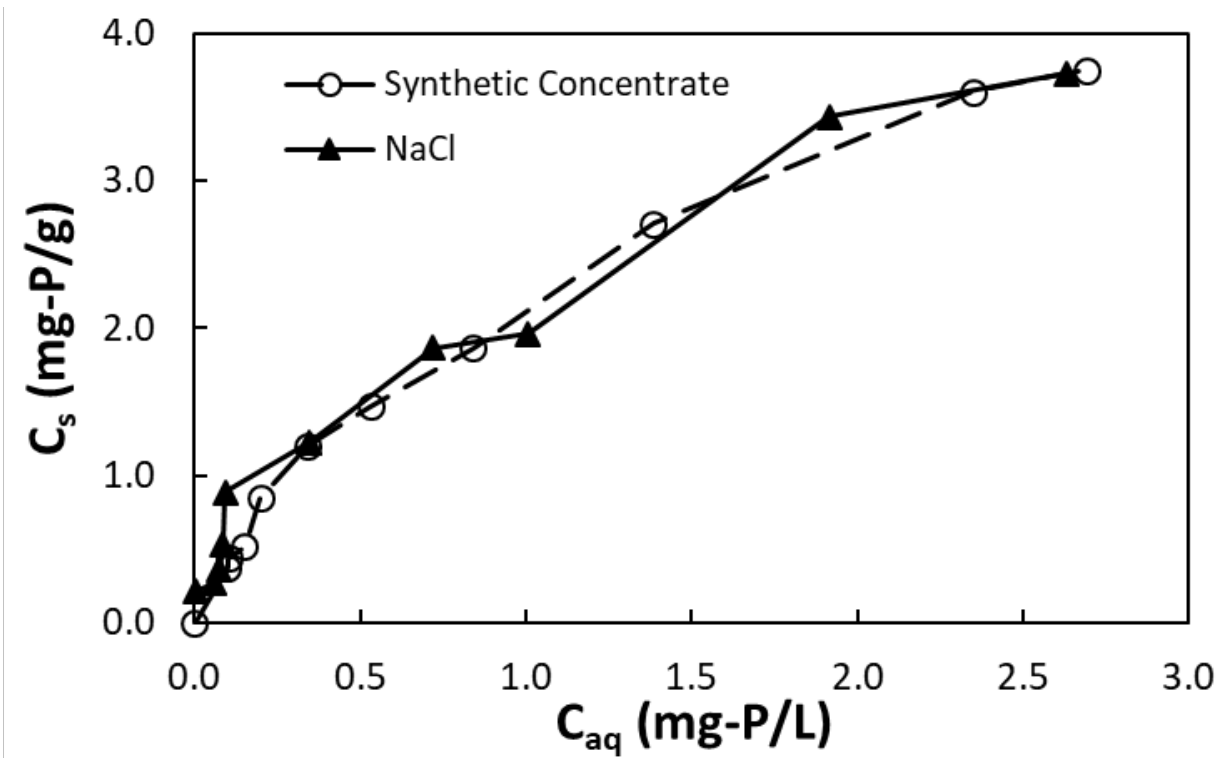

Figure 5. Adsorption isotherms after 24 hours elapsed for PT191 in $\mathrm{pH}=8.3$ synthetic NF concentrate and $\mathrm{NaCl}$ solutions, both at an ionic strength of $86.25 \mathrm{mmol} / \mathrm{L}$. Initial phosphorous concentration $=3.0 \mathrm{mg}-\mathrm{P} / \mathrm{L}$. 


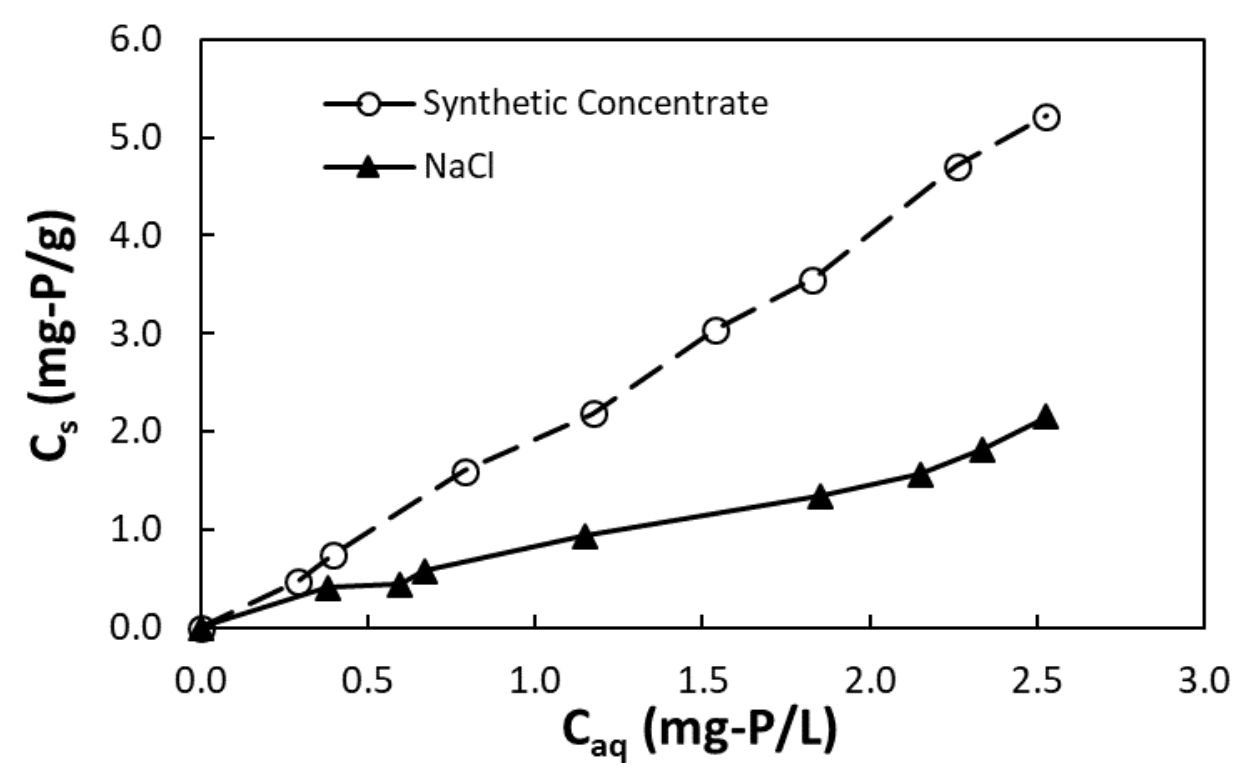

Figure 6. Adsorption isotherms after 24 hours elapsed for NTMP in $\mathrm{pH}=8.3$ synthetic NF concentrate and $\mathrm{NaCl}$ solutions, both at an ionic strength of $86.25 \mathrm{mmol} / \mathrm{L}$. Initial phosphorous concentration $=3.0 \mathrm{mg}-\mathrm{P} / \mathrm{L}$.

\subsection{Desorption Isotherms}

The kinetics of desorption were investigated by replacing the phosphonate containing solutions with simulated concentrate solutions at the same $\mathrm{pH}$ value of 8.3 . Figure 7 shows desorption (release) isotherms for PT191 at elapsed times ranging from 22 to 147 hours after replacing the solutions. For comparison, the adsorption (uptake) isotherm measured for PT191 after 147 hours elapsed is also shown in Figure 7. For adsorbed concentrations of 8.1 and 11.0 $\mathrm{mg}-\mathrm{P} / \mathrm{g}$, the desorption isotherms show greater loading than the uptake isotherm at 147 hours elapsed. This shows that release of phosphonate from the adsorbent is a slow process at a $\mathrm{pH}$ value of 8.3. Figure 7 also shows a desorption isotherm measured 24 hours after replacing the $\mathrm{pH}=8.3$ phosphonate containing solutions with $0.10 \mathrm{M} \mathrm{NaOH}$ solutions. Raising the $\mathrm{pH}$ resulted 
in significant phosphonate desorption. This can be attributed to electrostatic effects. Increasing the $\mathrm{pH}$ resulted in increasing the negative charge on the phosphonate, and increasing the negative charge on the akaganeite, whose $\mathrm{pH}$ of zero charge (pzc) is 7.2 [26].

Desorption of NTMP at pH values of 8.3 and 12.7 was similar to that observed for PT191, as shown in Figure 8. At all aqueous concentrations, there was more NTMP adsorbed in the desorption experiments than in the adsorption experiments after 147 hours elapsed. This shows that the equilibration process requires more than 147 hours.

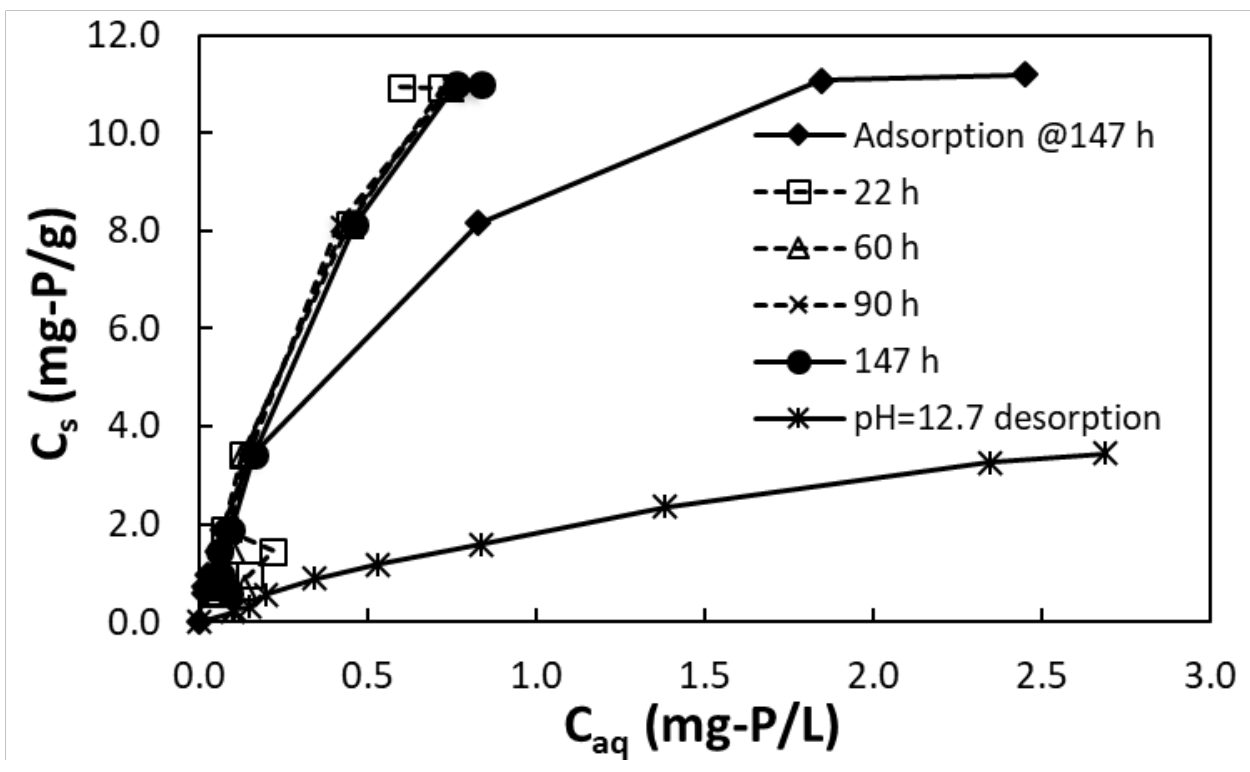

Figure 7. Desorption isotherms for PT191 at different elapsed times in fresh synthetic concentrate solutions at $\mathrm{pH}=8.3$ without phosphonate, and desorption by $\mathrm{pH}=12.7 \mathrm{NaOH}$ after 24 hours. Initial phosphorous concentration in the uptake experiments was $3.0 \mathrm{mg}-\mathrm{P} / \mathrm{L}$. 


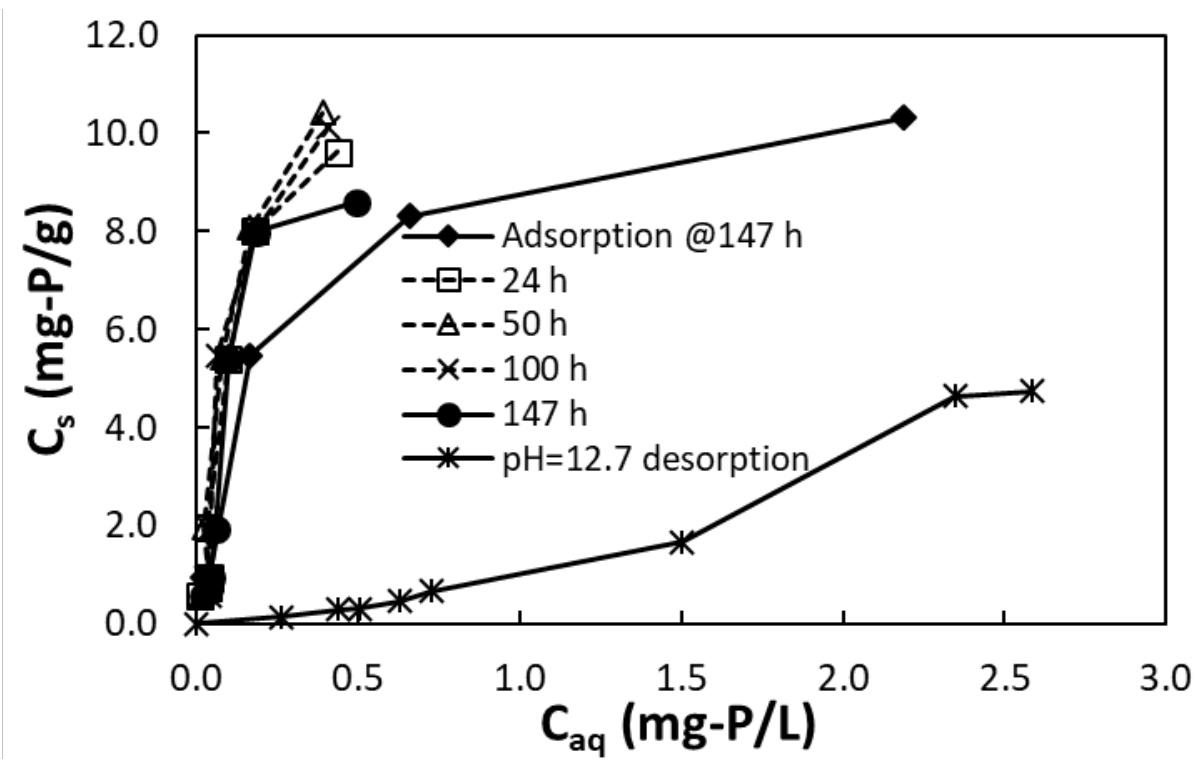

Figure 8. Desorption isotherms for NTMP at different elapsed times in fresh synthetic concentrate solutions at $\mathrm{pH}=8.3$ without phosphonate, and desorption by $\mathrm{pH}=12.7 \mathrm{NaOH}$ after 24 hours. Initial phosphorous concentration in the uptake experiments was $3.0 \mathrm{mg}-\mathrm{P} / \mathrm{L}$.

\subsection{Column Breakthrough Experiments}

Column breakthrough experiments were performed to determine if the kinetics of phosphonate adsorption are sufficiently fast to be used in a practical flow-through treatment system. Figure 9 shows PT191 and NTMP breakthrough profiles in packed columns operated with an empty bed contact time (EBCT) of 2.0 minutes and feed concentrations of $0.60 \mathrm{mg}-\mathrm{P} / \mathrm{L}$. This EBCT is on the low end of those used in commercial adsorbent systems [27]. The breakthrough profiles show that near complete removal was observed for $\sim 26800$ empty bed volumes for PT191 and for 2000 empty bed volumes for NTMP. This is performance is sufficient for use in practical treatment systems, which typically operate with EBCT ranging from 2 to 30 minutes [27]. 
Uptake of both phosphonate compounds was limited by slow adsorption kinetics. For the PT191, uptake by 641700 bed volumes after 8.9 days elapsed was $3.07 \mathrm{mg}-\mathrm{P} / \mathrm{g}$. This is approximately half of the adsorption capacity of $6.1 \mathrm{mg}-\mathrm{P} / \mathrm{g}$ measured for an aqueous concentration of $0.6 \mathrm{mg}-\mathrm{P} / \mathrm{L}$ after 6 days (147h) elapsed, as shown in Figure 1. For NTMP, the uptake of $4.38 \mathrm{mg}-\mathrm{P} / \mathrm{g}$ after 12.5 days was also lower than the capacity of $6.9 \mathrm{mg}-\mathrm{P} / \mathrm{g}$ measured after 147 hours elapsed for an aqueous concentration of $0.6 \mathrm{mg}-\mathrm{P} / \mathrm{L}$. For both columns, the early breakthrough utilizing only $50-64 \%$ of the 147 -hour capacity can be attributed to the slow adsorption kinetics.

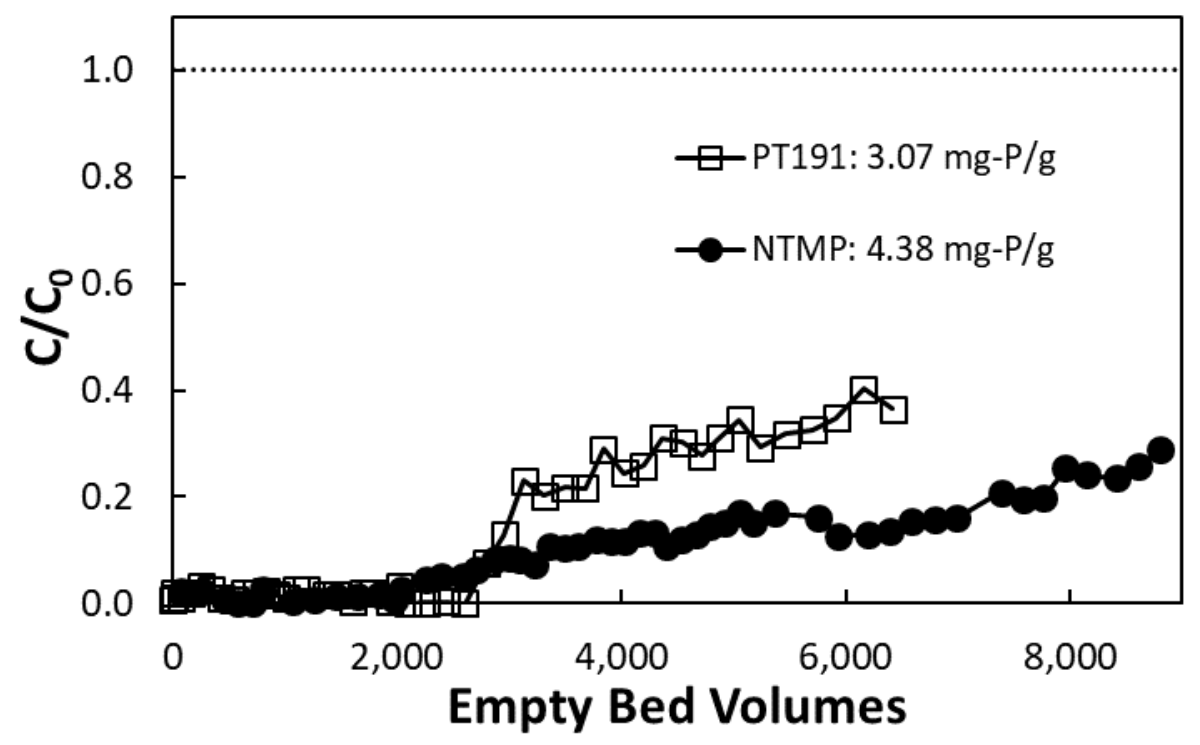

Figure 9. Breakthrough profiles for PT191 and NTMP from $\mathrm{pH}=8.3$ simulated NF concentrate solutions in columns of GFH media operated at an EBCT of 2.0 minutes and feed concentrations of $0.60 \mathrm{mg}-\mathrm{P} / \mathrm{L}$. 


\subsection{Column Regeneration Experiments}

During adsorbent regeneration there are several opposing factors that need to be minimized,

these include: 1) the mass of base used for producing the regenerant solution; 2) the volume of the regenerant solution; and 3) the time required for regeneration. Optimizing these parameters requires an understanding of the mechanisms controlling desorption. The rate of desorption can be controlled by either kinetic or equilibrium effects. Kinetic limitations on desorption include the reaction rate of the desorption reaction and diffusional mass transfer. Equilibrium limitations on the desorption rate primarily depend on differences in the adsorption isotherms under loading and regeneration conditions, and in this case depend primarily on the solution $\mathrm{pH}$ value and temperature. Insight into these effects can be gained by varying the regenerant solution concentration, flow rate, and temperature.

Figure 10 shows the fraction of PT191 desorbed versus eluant bed volumes from a column of GFH using $0.10 \mathrm{~mol} / \mathrm{L}$ and $1.0 \mathrm{~mol} / \mathrm{L} \mathrm{NaOH}$ solutions. Using a $0.10 \mathrm{~mol} / \mathrm{L} \mathrm{NaOH}$ solution at $20{ }^{\circ} \mathrm{C}, 39 \%$ of the adsorbed PT191 was desorbed after 30 bed volumes (1050 minutes), however, after that point, the desorption rate was much slower. An additional 300 bed volumes $(10,500$ min) released only $39 \%$ more PT191. This indicates that the release rate for the slow desorbing fraction was an order of magnitude lower than that for the fast desorbing fraction. This type of desorption behavior is often attributed to intragranular diffusional mass transfer limitations [22].

The effect of the eluant concentration on PT191 desorption suggests that some of this dual rate behavior can be attributed to equilibrium effects. Increasing the eluant concentration from 0.10 to $1.0 \mathrm{~mol} / \mathrm{L}$ increased the release rate of both the fast and slow desorbing fractions. This indicates that the release rate over the first $\sim 50$ bed volumes in the $0.10 \mathrm{~mol} / \mathrm{L} \mathrm{NaOH}$ solution was not limited by mass transfer limitations, since the eluant concentration should only 
minimally affect rates of diffusion. In the $1.0 \mathrm{~mol} / \mathrm{L}$ eluant, the weaker adsorption at higher $\mathrm{pH}$ values increased the thermodynamic driving force for PT191 desorption and increased the mass of fast desorbing PT191. This is an equilibrium effect.

An increase in temperature should affect both kinetic and equilibrium limitations on the desorption rate. An increase in temperature should increase both the rate of the desorption reaction and the rate of intragranular diffusion. An increase in temperature should also affect the equilibrium partitioning between adsorbed and solution phases. According to quantum chemistry simulations, chemisorption of NTMP on ferric hydroxide is exothermic, and thus there should be less adsorption at higher temperature [9]. As shown in Figure 10, increasing the temperature to $50{ }^{\circ} \mathrm{C}$ during the regeneration process increased the release rate of the fast desorbing fraction. Increasing the temperature by $30{ }^{\circ} \mathrm{C}$ increased the initial release rate (first $25 \%$ desorbed) by a factor of 3.6. This increase in rate corresponds to an apparent activation energy for the desorption process of $29 \mathrm{~kJ} / \mathrm{mol}$. While this is not the true activation energy, this value is much higher than apparent activation energies for aqueous diffusion. According to the WilkeChang equation, diffusion coefficients calculated for NTMP at $20{ }^{\circ} \mathrm{C}$ and $50{ }^{\circ} \mathrm{C}$ yield an apparent activation energy of $0.023 \mathrm{~kJ} / \mathrm{mol}$ [28]. Thus, it is not likely that the initial release of PT191 was limited by a simple aqueous diffusional mass transport process. The small impact of the increase in temperature on the fraction of slowly released PT191 suggests that the impact of temperature on equilibrium partitioning was small. 


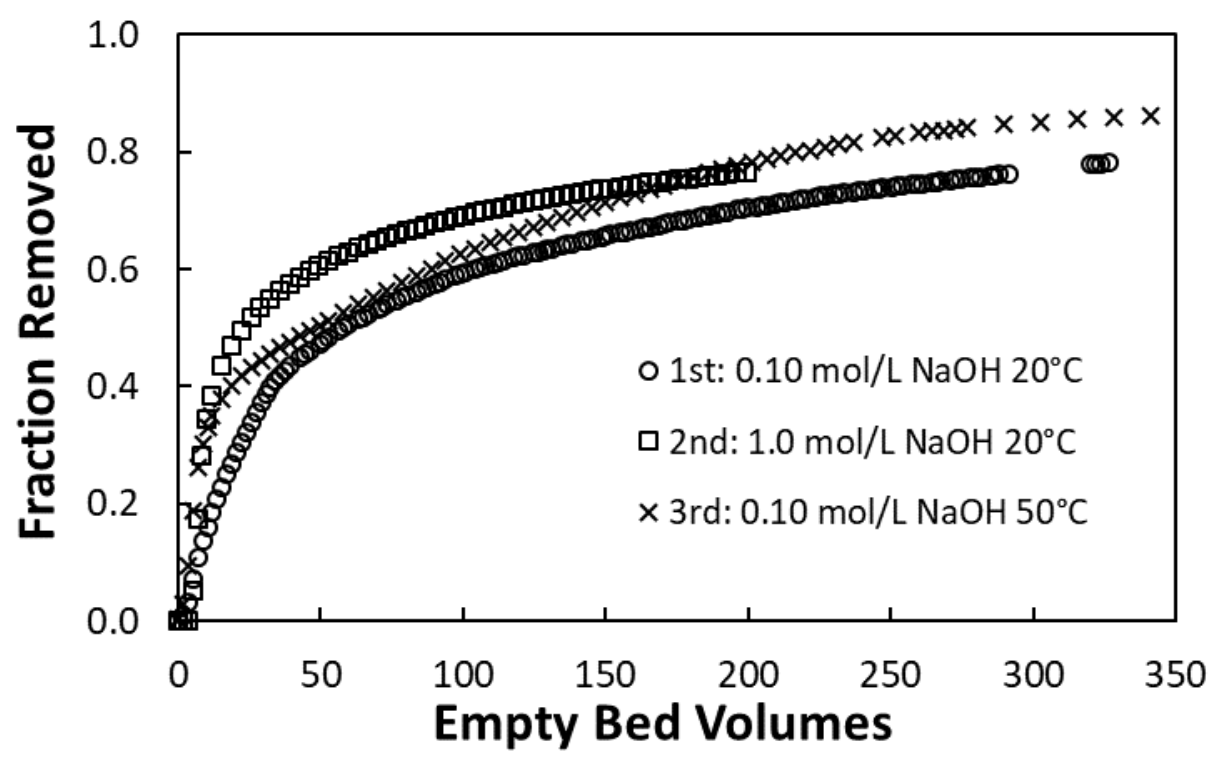

Figure 10. Fraction of PT191 removed from GFH as a function of regenerant solution bed volumes at a flow rate of $0.05 \mathrm{ml} / \mathrm{min}(35 \mathrm{~min} \mathrm{EBCT})$.

Further insight into the mechanisms controlling release of adsorbed phosphonate can be seen by varying the flow rate and eluant concentration during a single experiment. In these experiments, the regeneration cycle was divided into 4 parts: a) $0.10 \mathrm{~mol} / \mathrm{L} \mathrm{NaOH}$ at $0.05 \mathrm{ml} / \mathrm{min}$; b) $0.10 \mathrm{~mol} / \mathrm{L} \mathrm{NaOH}$ at $0.25 \mathrm{ml} / \mathrm{min}$; c) $1.0 \mathrm{~mol} / \mathrm{L} \mathrm{NaOH}$ at $0.25 \mathrm{ml} / \mathrm{min}$; and d) $1.0 \mathrm{~mol} / \mathrm{L}$ $\mathrm{NaOH}$ at $0.05 \mathrm{ml} / \mathrm{min}$. The flow rate at $0.05 \mathrm{ml} / \mathrm{min}$ corresponds to an empty bed contact time of $35 \mathrm{~min}$ and $0.25 \mathrm{ml} / \mathrm{min}$ corresponds to $7.0 \mathrm{~min}$. Figure 11 shows the fraction of NTMP removed from a column of GFH using $0.10 \mathrm{~mol} / \mathrm{L} \mathrm{NaOH}$ at a flow rate of $0.05 \mathrm{ml} / \mathrm{min}$ for 5700 min (163 bed volumes). Similar to the PT191, there was a fast desorbing fraction and a slow desorbing fraction. At 5700 min elapsed, the eluant flow rate was increased to $0.25 \mathrm{ml} / \mathrm{min}$. This resulted in a factor of 4.1 increase in the NTMP release rate from $4.40 \times 10^{-4}$ to $1.82 \times 10^{-3}$ $\mathrm{mg}-\mathrm{NTMP} / \mathrm{min}$. This indicates that equilibrium factors were limiting the desorption rate of the slow desorbing fraction. At 6400 minutes elapsed the eluant concentration was increased to 1.0 
$\mathrm{mol} / \mathrm{L}$. This resulted in a factor of 5.4 increase in the desorption rate from $1.21 \times 10^{-3}$ to $6.55 \times 10^{-3}$ $\mathrm{mg}-\mathrm{NTMP} / \mathrm{min}$, which is also indicative of an equilibrium effect. Similar results were observed for PT191 desorption, as shown in Figure 12. Increasing the eluant flow rate from 0.05 to 0.25 $\mathrm{ml} /$ min increased the desorption rate by a factor of 3.9. Increasing the eluant concentration from 0.10 to $1.0 \mathrm{~mol} / \mathrm{L}$ increased the desorption rate by a factor of 6.7 . Thus, equilibrium considerations strongly affected the release rate of the slow desorbing fraction of PT191. Overall, removal of phosphonate from the GFH media was much more difficult than regeneration of weak acid ion exchange media, which typically requires fewer than 10 bed volumes for near complete regeneration [27]. The difficulty in removing adsorbed phosphonate stems from its strong adsorption, even in $1.0 \mathrm{~mol} / \mathrm{L} \mathrm{NaOH}$ solutions, and from the slow kinetics of the desorption reactions.

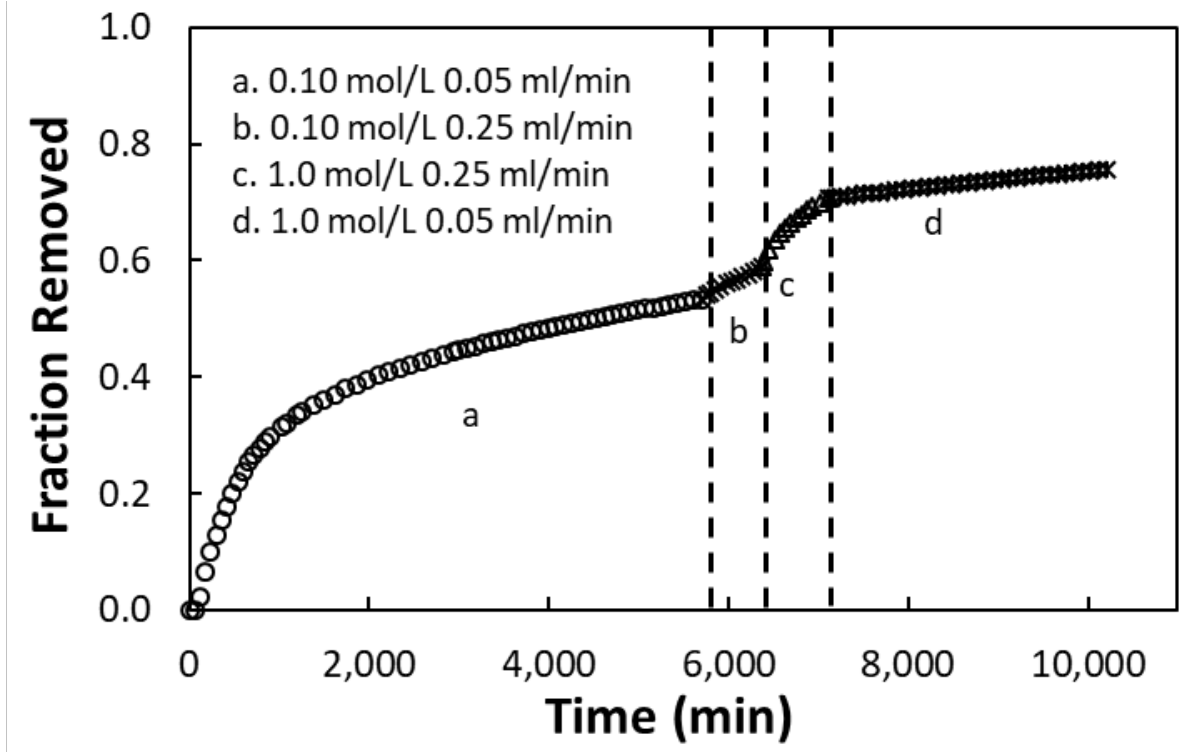

Figure 11. Fraction of adsorbed NTMP removed from GFH under four different elution conditions. 


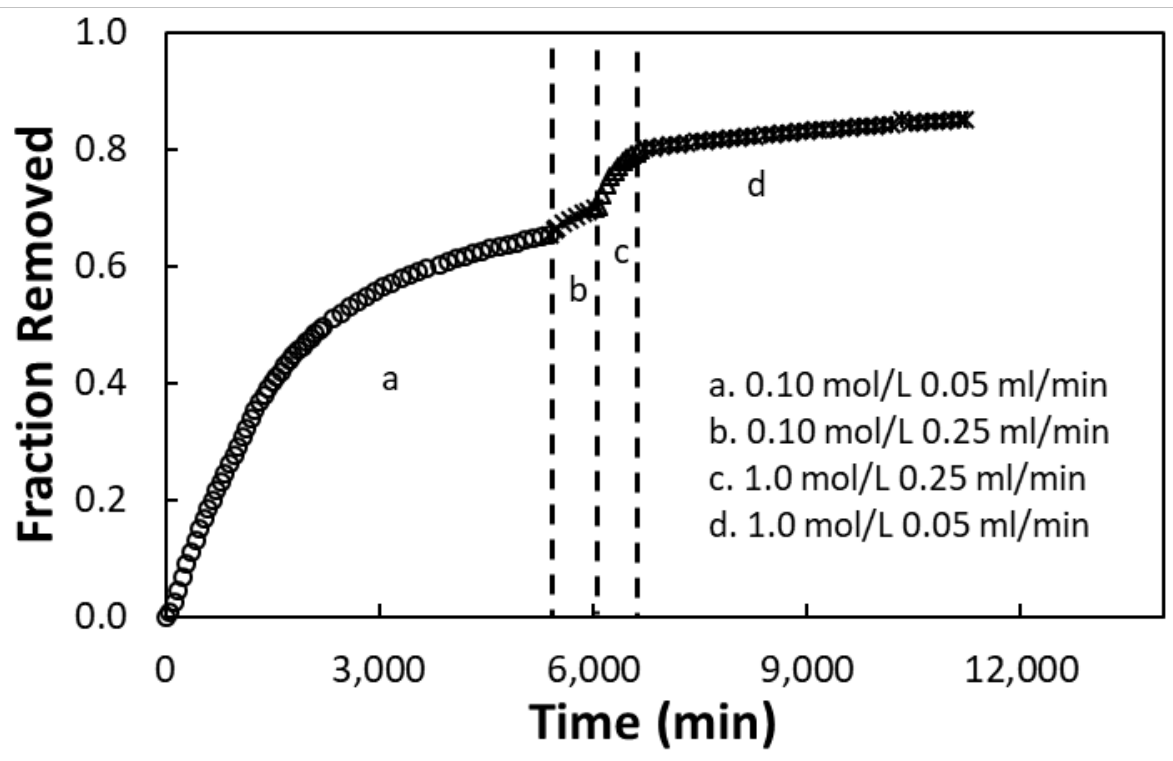

Figure 12. Fraction of adsorbed PT191 removed from GFH under four different elution conditions.

\subsection{Adsorbent Reuse}

The incomplete regeneration of the GFH adsorbent may result in decreased phosphonate uptake during subsequent adsorption cycles. Figure 13 shows three PT191 breakthrough experiments on a column of GFH, and Table 5 summarizes the mass of phosphorous adsorbed and desorbed during each experiment. During the first breakthrough experiment, near complete PT191 removal was observed for 2600 bed volumes and the total uptake was $3.07 \mathrm{mg}-\mathrm{P} / \mathrm{g}$ after 6400 bed volumes. When this column was regenerated using $0.10 \mathrm{~mol} / \mathrm{L} \mathrm{NaOH}$, only $78 \%$ of the adsorbed PT191 was removed after 327 bed volumes. The incomplete regeneration resulted in immediate breakthrough of PT191 during the second breakthrough experiment. However, the uptake of PT191 over the first 6000 bed volumes of $4.04 \mathrm{mg}-\mathrm{P} / \mathrm{g}$ during the second breakthrough was greater than the uptake during the first breakthrough experiment after 6000 bed volumes. 
During regeneration after the second adsorption experiment, only $66 \%$ of the total PT191 in the column was desorbed. However, the uptake over the first 6000 bed volumes during the third breakthrough experiment of $2.91 \mathrm{mg}-\mathrm{P} / \mathrm{g}$ was close to that for the first experiment ( $2.89 \mathrm{mg}-\mathrm{P} / \mathrm{g}$ ), despite the fact that the column already contained $1.62 \mathrm{mg}-\mathrm{P} / \mathrm{g}$ at the start of the third breakthrough. After the third regeneration, the PT191 mass balance difference between integrating the uptake and desorption profiles yielded a residual loading of $1.83 \mathrm{mg}-\mathrm{P} / \mathrm{g}$. Extraction of the adsorbent samples yielded a residual of $1.66 \mathrm{mg}-\mathrm{P} / \mathrm{g}$, indicating a mass balance error of $\sim 10 \%$.

The effect of incomplete regeneration on subsequent adsorption capacity was greater for NTMP than for the PT191, as shown in Figure 14. Similar to the PT191, the regeneration efficiency was $78 \%$ after the first breakthrough experiment. However, the NTMP uptake over the first 6000 bed volumes was reduced by $28 \%$ in the second breakthrough experiment. The greater effect of incomplete regeneration on subsequent uptake for NTMP than for the PT191 is consistent with NTMP having more phosphonate functional groups than PT191. Given that all six of the phosphonic acid groups are near completely ionized at $\mathrm{pH}=8.3$, exchange of a NTMP ligand for a $-\mathrm{H}_{2} \mathrm{O}$ ligand will result in a significant decrease in the surface charge of the adsorbent. This decrease in surface charge will decrease the energetic favorability for further NTMP adsorption. If the NTMP is more negatively charged than the PT191 adsorbate, the adverse effects of incomplete regeneration would be greater for the NTMP. 


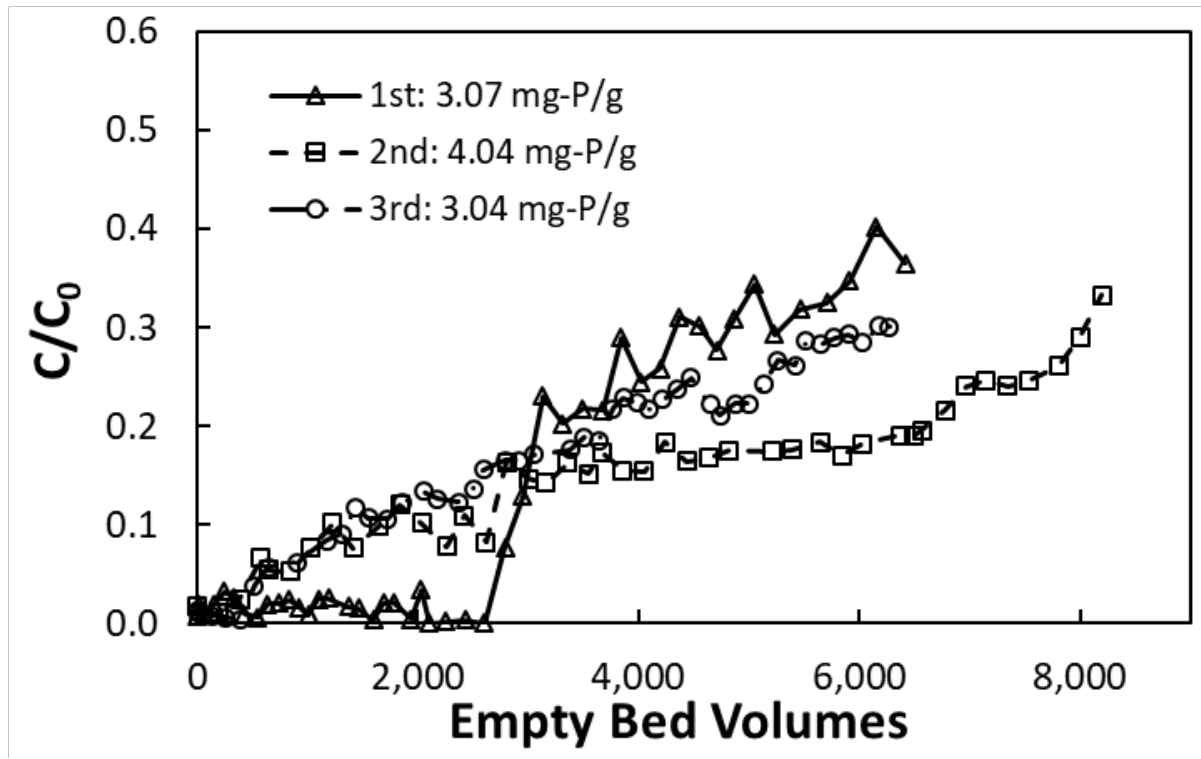

Figure 13. Column breakthrough profiles in simulated NF concentrate at $\mathrm{pH}=8.3$ for PT191 on GFH with feed concentrations of $0.60 \mathrm{mg}-\mathrm{P} / \mathrm{L}$. Uptake during each breakthrough experiment is shown for each data set. The same column was loaded and regenerated three times using 0.10 $\mathrm{mol} / \mathrm{L}$ and $1.0 \mathrm{~mol} / \mathrm{L} \mathrm{NaOH}$. 


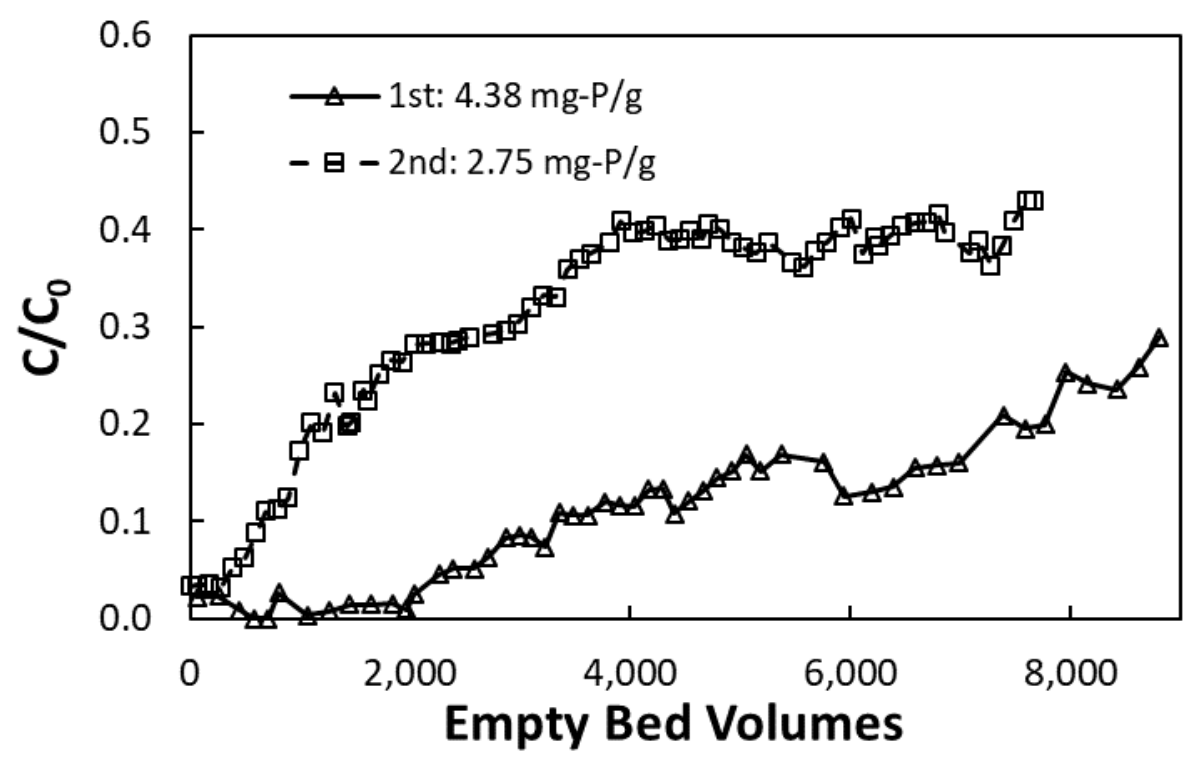

Figure 14. Column breakthrough profiles for NTMP in simulated NF concentrate at $\mathrm{pH}=8.3$ on GFH with feed concentrations of $0.60 \mathrm{mg} \mathrm{P} / \mathrm{L}$. Uptake during each breakthrough experiment is shown for each data set. The same column was loaded and regenerated two times using 0.10 $\mathrm{mol} / \mathrm{L}$ and $1.0 \mathrm{~mol} / \mathrm{L} \mathrm{NaOH}$.

Table 5. The loading and regeneration of PT191 and NTMP on GFH. (Units are mg-P/g)

\begin{tabular}{cccccccc}
\hline \multirow{2}{*}{ PT191 } & Uptake by 6000 & Final & Total in & Regeneration & Residual & Recovery \% & $\begin{array}{c}\text { Extracted } \\
\text { Residual }\end{array}$ \\
& Bed Volumes & Uptake & Column & & & & \\
1st & 2.89 & 3.07 & 3.07 & 2.40 & 0.67 & $78 \%$ & \\
2nd & 3.04 & 4.05 & 4.72 & 3.10 & 1.62 & $66 \%$ & \\
3rd & 2.91 & 3.04 & 4.66 & 2.83 & 1.83 & $61 \%$ & \\
Total & & 10.16 & & 8.33 & 1.83 & & 1.66 \\
\hline \multirow{2}{*}{ NTMP } & Uptake by 6000 & Final & Total in & Regeneration & Residual & Recovery \% & Extracted \\
& Bed Volumes & Loading & Column & & & & \\
1st & 3.09 & 4.38 & 4.38 & 3.40 & 0.98 & $78 \%$ & \\
2nd & 2.24 & 2.75 & 3.73 & 2.08 & 1.65 & $56 \%$ & \\
Total & & 7.13 & & 5.48 & 1.65 & & 1.83 \\
\hline
\end{tabular}




\section{Conclusion}

This research showed that phosphonate compounds adsorb strongly to GFH, even in the presence of high concentrations of other anions. This indicates that the adsorption mechanism involves inner-sphere complexation. The initial concentration effects shown after 24 hours elapsed for both PT191 and NTMP indicate that the adsorption reactions are not kinetically reversible. Strong phosphonate adsorption, even in high $\mathrm{pH}$ solutions, renders conventional regeneration methods impractical. More research is needed on improving regeneration for GFH to be considered a regenerable adsorbent for phosphonate antiscalants.

\section{Acknowledgement}

This research was funded in part by the National Science Foundation (CBET-1235596).

\section{Conflict of Interest Disclosure}

The authors declare no competing financial interest. 


\section{References}

[1] E.C. Hennes-Morgan, N.T. De Oude, Detergents, in: Handb. Ecotoxicol., Blackwell Publishing Ltd., Oxford, UK, 2009: pp. 594-618. doi:10.1002/9781444313512.ch29.

[2] B. Nowack, Environmental chemistry of phosphonates, Water Res. 37 (2003) 2533-2546. doi:10.1016/S0043-1354(03)00079-4.

[3] R. Bond, S. Veerapaneni, Zero Liquid Discharge for Inland Desalination, Denver, Colorado, 2007.

[4] M.A. Aghdam, F. Zraick, J. Simon, J. Farrell, S.A. Snyder, A novel brine precipitation process for higher water recovery, Desalination. 385 (2016) 69-74. doi:10.1016/j.desal.2016.02.007.

[5] X.X. Wang, Y.H. Wu, T.Y. Zhang, X.Q. Xu, G.H. Dao, H.Y. Hu, Simultaneous nitrogen, phosphorous, and hardness removal from reverse osmosis concentrate by microalgae cultivation, Water Res. 94 (2016) 215-224. doi:10.1016/j.watres.2016.02.062.

[6] L. Boels, K.J. Keesman, G.J. Witkamp, Adsorption of phosphonate antiscalant from reverse osmosis membrane concentrate onto granular ferric hydroxide, Environ. Sci. Technol. 46 (2012) 9638-9645. doi:10.1021/es302186k.

[7] L. Boels, Removal and Recovery of Phosphonate antiscalants, TU Delft, Delft University of Technology, 2012. doi:10.4233/uuid:3191027b-3f7c-484c-9a9c-d914d2e3dcea.

[8] Y. Chen, J.C. Baygents, J. Farrell, Understanding Competitive Adsorption of NTMP and Silica on Ferric Hydroxide, Environ. Eng. Sci. (2017) ahead of print. doi:10.1089/ees.2016.0441.

[9] R.J. Martínez, J. Farrell, Understanding Nitrilotris(methylenephosphonic acid) reactions with ferric hydroxide, Chemosphere. 175 (2017) 490-496. 
doi:10.1016/j.chemosphere.2017.02.015.

[10] K. Popov, H. Rönkkömäki, L.H.J. Lajunen, Critical evaluation of stability constants of phosphonic acids (IUPAC Technical Report), Pure Appl. Chem. 73 (2001) 1641-1677. doi:10.1351/pac200173101641.

[11] B.C. Barja, M.I. Tejedor-Tejedor, M.A. Anderson, Complexation of Methylphosphonic Acid with the Surface of Goethite Particles in Aqueous Solution, Langmuir. 15 (1999) 2316-2327. doi:10.1021/la980540y.

[12] B.C. Barja, M. Dos Santos Afonso, Aminomethylphosphonic acid and glyphosate adsorption onto goethite: A comparative study, Environ. Sci. Technol. 39 (2005) 585-592. doi:10.1021/es035055q.

[13] C.M. Jonsson, P. Persson, S. Sjöberg, J.S. Loring, Adsorption of Glyphosate on Goethite ( $\alpha-\mathrm{FeOOH})$ : Surface Complexation Modeling Combining Spectroscopic and Adsorption Data, Environ. Sci. Technol. 42 (2008) 2464-2469. doi:10.1021/es070966b.

[14] J. Sheals, S. Sjöberg, P. Persson, Adsorption of glyphosate on goethite: molecular characterization of surface complexes., Environ. Sci. Technol. 36 (2002) 3090-5.

[15] L. Tribe, K.D. Kwon, C.C. Trout, J.D. Kubicki, Molecular orbital theory study on surface complex structures of glyphosate on goethite: calculation of vibrational frequencies., Environ. Sci. Technol. 40 (2006) 3836-3841. doi:10.1021/es052363a.

[16] B. Nowack, A.T. Stone, The Influence of Metal Ions on the Adsorption of Phosphonates onto Goethite, Environ. Sci. Technol. 33 (1999) 3627-3633. doi:10.1021/ES9900860.

[17] O.S. Thirunavukkarasu, T. Viraraghavan, K.S. Subramanian, Arsenic removal from drinking water using granular ferric hydroxide, Water SA. 29 (2003) 161-170. doi:10.4314/wsa.v29i2.4851. 
[18] L. Wang, W.. Condit, A.. Chen, Technology selection and system design US EPA arsenic removal technology demonstration program round 1, National Risk Management Research Laboratory, Office of Research and Development, US Environmental Protection Agency, 2004. https://nepis.epa.gov/Exe/ZyPDF.cgi/2000D1MP.PDF?Dockey=2000D1MP.PDF (accessed June 13, 2016).

[19] J. Bundschuh, H. Hollander, L.Q. Ma, eds., In-situ remediation of arsenic-contaminated sites, CRC Press, 2014.

[20] E. Zeiher, C. Soderquist, Method for inhibiting scale formation and/or dispersing iron in reverse osmosis systems, 1994. https://www.google.com/patents/US5358640 (accessed June 8, 2016).

[21] OriginLab Corporation, Origin 8.5 Press Release, (2010). http://www.originlab.com/index.aspx?go=Company/NewsAndEvents/PressRoom\&pid=17 20 (accessed June 8, 2017).

[22] C.C. Fuller, J.A. Davis, G.A. Waychunas, Surface chemistry of ferrihydrite: Part 2. Kinetics of arsenate adsorption and coprecipitation, Geochim. Cosmochim. Acta. 57 (1993) 2271-2282. doi:10.1016/0016-7037(93)90568-H.

[23] G. He, M. Zhang, G. Pan, Influence of $\mathrm{pH}$ on initial concentration effect of arsenate adsorption on TiO2 surfaces: Thermodynamic, DFT, and EXAFS interpretations, J. Phys. Chem. C. 113 (2009) 21679-21686. doi:10.1021/jp906019e.

[24] W. Yang, N. Zhao, N. Zhang, W. Chen, A.T. Kan, M.B. Tomson, Time-dependent adsorption and resistant desorption of arsenic on magnetite nanoparticles: kinetics and modeling, Desalin. Water Treat. 44 (2012) 100-109. doi:10.1080/19443994.2012.691808.

[25] J. Farrell, B.K. Chaudhary, Understanding arsenate reaction kinetics with ferric 
hydroxides, Environ. Sci. Technol. 47 (2013) 8342-8347. doi:10.1021/es4013382.

[26] R.M. Cornell, U. Schwertmann, The Iron Oxides: Structure, Properties, Reactions, Occurrences and Uses, Second Edition - Cornell - Wiley Online Library, John Wiley \& Sons, 2003.

[27] M. L. Davis, Water and Wastewater Engineering: Design Principles and Practice, McGraw-Hill, New York, 2010.

[28] C.R. Wilke, P. Chang, Correlation of diffusion coefficients in dilute solutions, AIChE J. 1 (1955) 264-270. doi:doi:10.1002/aic.690010222. 